\title{
Effect evaluation and influencing factors of stratified water injection in low permeability reservoir
}

\author{
Xin $\mathrm{Bai}^{1}$, Shiyan $\mathrm{Hao}^{2}$, Chunfen $\mathrm{Guo}^{1}{ }^{1}$, , Shenglin Yao ${ }^{1}$ \\ ${ }^{1}$ Yanchang Oilfield Limited Company, Yan'an Shaanxi 716000, China \\ ${ }^{2}$ Shaanxi Yanchang Petroleum(Group)Co, Ltd, Xi'an Shaanxi 710000, China
}

\begin{abstract}
The main production layers in Danba oil area of Yanchang oilfield are Chang $4+5$ and Chang 6 oil layers, which are the main development areas for increasing reserves and production. In view of the unclear influencing factors of water injection effect and the disunity of effect evaluation in the study area, the stratified water injection effect evaluation and influencing factors of low permeability reservoir are studied by means of production data statistical analysis and numerical simulation. The results show that the effect of water injection in the study area is affected by five factors: intraformational heterogeneity, interlayer heterogeneity, interlayer pressure difference, fracture and water injection timing, the results show that the water injection effect is obvious in the study area by using the five indexes of water drive reserves producing degree, water storage rate, water drive index, oil recovery rate and water drive control degree. The research results provide ideas for the study of high-efficiency separate layer water injection in low permeability reservoir, and provide guidance for the next step of potential mining.
\end{abstract}

\section{Introduction}

With the deepening of the exploitation, the oil production will decline. Water injection can effectively displace the crude oil in the reservoir, maintain the formation pore pressure, achieve high efficiency and stable production, and improve the development effect of the oilfield[1]. Compared with general water injection, separate layer water injection can realize fine water injection, with high producing degree of water drive reserves, avoiding local water flooding and ensuring water injection efficiency to the greatest extent. For low permeability reservoirs, there are three kinds of separate injection methods: surface separate injection, eccentric bailing separate injection and concentric integrated separate injection[2]. Surface separate injection is suitable for large angle deviated wells, directional wells and deep wells; eccentric bailing and separate injection is suitable for separate layer water injection with splitter; concentric integrated separate injection uses casing protection packer and jet well washer to realize separate layer water injection[3]. There are many factors affecting the effect of stratified water injection, such as interlayer interference, poor water injection effect due to different physical properties, good water absorption effect in high permeability formation, poor water absorption effect in low permeability formation and low water injection efficiency[4].

Separate layer water injection can improve injection production profile, maintain formation energy and avoid water breakthrough in oil wells. There is no unified standard for separate layer water injection effect evaluation. At present, it mainly evaluates from the perspective of economic benefits, such as the degree of production of water drive reserves, oil recovery rate, water cut rise rate, dynamic recovery rate and so on, ignoring the water injection utilization index, such as water storage rate, water drive index, water consumption index and so on. Firstly, the influencing factors of stratified water injection in low permeability reservoir are defined, and the differences of influencing factors in different blocks are analyzed[5]. Then, on the basis of economic benefit evaluation parameters, combined with water injection utilization index, the effect of stratified water injection is evaluated, and an evaluation system suitable for stratified water injection in the study area is formed[6]. This study provides a reference for stratified water injection in low permeability reservoir and a new idea for evaluation of water injection effect.

\section{2 methods and materials}

The production data include: well basic information (well coordinate, well curve, well stratification), lithology data, water injection data over the years, and fluid production data. The production data are used to calculate the characterization parameters: water storage rate, canal index and oil recovery rate.

$$
W_{f}=\frac{W_{i}-W_{p}}{W_{i}} * 100 \%
$$

Where: WF: water storage rate, $\%$; Wi: water injection volume, $\mathrm{m}^{3}$; WP: recovery, $\mathrm{m} 3$.

\footnotetext{
*Corresponding author: mma0405@sina.com
} 


$$
S=\frac{W_{i}-W_{p}}{N_{p} B_{\circ}}
$$

Where: s: water drive index, \%; Wi: water injection volume, m3; WP: recovery, m3; NP: cumulative oil production, m3; Bo: volume coefficient of crude oil.

\section{Results and analysis}

\section{1 analysis of influencing factors of development effect}

\subsection{1 intraformational heterogeneity}

According to table 1, it can be concluded that the heterogeneity in different blocks is different, the range of Chang $4+5$ is 8.9 , the outburst coefficient is 2.3 , and the variation coefficient is 0.58 ; the eastern combined mining unit has a long $4+5$ range of 5.3 , a outburst coefficient of 1.8 and a variation coefficient of 0.50 ; in the south, the range of single mining length $4+5$ is 9.6 , the outburst coefficient is 1.9 , and the variation coefficient is 0.56 ; the range of $4+5$ is 6.2 , the outburst coefficient is 1.6 and the variation coefficient is 0.53.According to the classification standard of intraformational heterogeneity, the west is heterogeneous extremely heterogeneous, the East, South and southeast are relatively homogeneous, and the heterogeneity in the west is stronger than that in the East, Southeast and south.

Table1. Classification standard of heterogeneity degree of sandstone reservoir

\begin{tabular}{|c|c|c|c|c|}
\hline $\begin{array}{c}\text { Coefficient of } \\
\text { variation }\end{array}$ & $\mathbf{0 . 1} \sim \mathbf{0 . 3}$ & $\mathbf{0 . 3} \sim \mathbf{0 . 7 5}$ & $\begin{array}{c}\mathbf{0 . 7 5} \\
\mathbf{1 . 3}\end{array}$ & $>\mathbf{1 . 3}$ \\
\hline $\begin{array}{c}\text { Breakthrough } \\
\text { coefficient }\end{array}$ & 1.0 & $1.0 \sim 2.0$ & $2.0 \sim 4.0$ & $>4.0$ \\
\hline range & 1.2 & $2 \sim 10$ & $10 \sim 100$ & $>100$ \\
\hline $\begin{array}{c}\text { Degree of } \\
\text { heterogeneity }\end{array}$ & $\begin{array}{c}\text { Homogene } \\
\text { ous layer }\end{array}$ & $\begin{array}{c}\text { More } \\
\text { homogeneou } \\
\text { s layer }\end{array}$ & $\begin{array}{c}\text { Heteroge } \\
\text { neous } \\
\text { layer }\end{array}$ & $\begin{array}{c}\text { Very } \\
\text { heterogen } \\
\text { eous layer }\end{array}$ \\
\hline
\end{tabular}

\subsection{2 interlayer heterogeneity}

According to figure 1 , it can be concluded that the distribution frequency of Chang $4+5$ interlayer is $73.2 \%$ in the south, $70.6 \%$ in the west, $53.4 \%$ in the southeast and $34.6 \%$ in the East. The distribution law is as follows: Southern single mining unit $>$ Western combined mining unit $>$ southeast single mining unit $>$ Eastern combined mining unit. The proportion of uneven water absorption is $50.0 \%$ in the south, $45.5 \%$ in the west, $33.3 \%$ in the southeast and $37.9 \%$ in the East. The order of distribution is southern single mining unit $>$ Western combined mining unit $>$ southeast single mining unit $>$ Eastern combined mining unit. It can be concluded that: the proportion of uneven water absorption is positively correlated with the distribution of interlayer. The higher the distribution frequency of interlayer, the higher the proportion of uneven water absorption, the stronger the heterogeneity of reservoir, which is more conducive to the implementation of stratified water injection, especially for the thickness of interlayer greater than $2 \mathrm{~m}$, which is suitable for large-scale interlayer water injection[7].

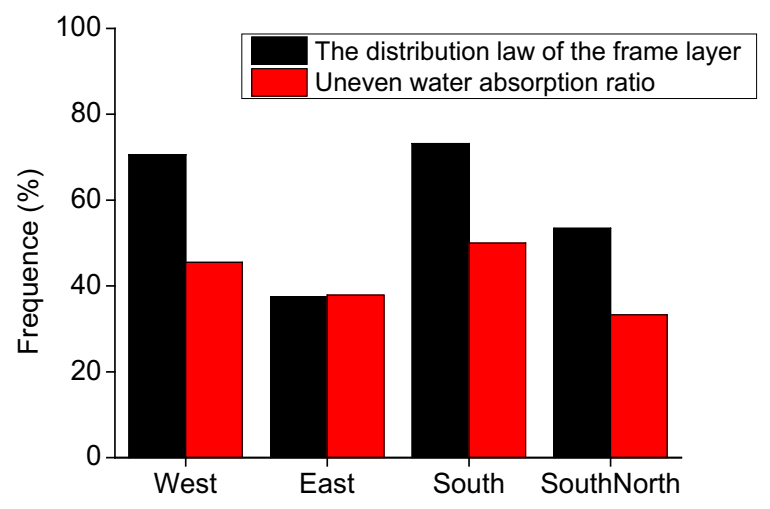

Figure 1. Frequency map of interlayer distribution in study area

\subsection{3 interlayer pressure difference}

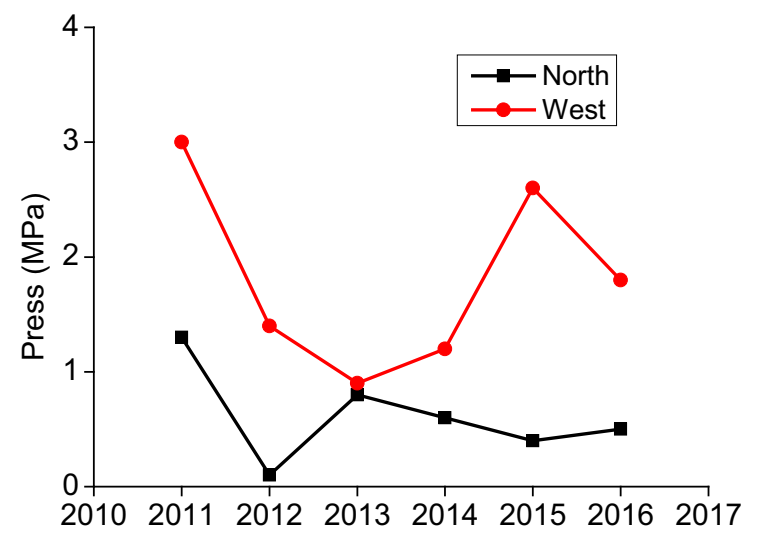

Figure 2. Pressure difference curve of combined production over the years

It can be concluded from Figure 2 that the combined production pressure difference in the East is between $0.1 \mathrm{MPa}$ and $1.3 \mathrm{mpa}$, with an average value of $0.55 \mathrm{mpa}$; the pressure difference of commingled production in the west is between $0.81 \mathrm{mpa}$ and $2.92 \mathrm{mpa}$, with an average value of $1.83 \mathrm{mpa}$. The larger the interlayer pressure difference is, the more unfavorable it is to separate layer water injection[8]. The combined production pressure difference in the west is greater than that in the East, and the separate layer water injection effect is poor. During the period of 2012-2014, the pressure difference in the East decreased significantly, and the pressure difference in the East increased locally, because during this period, the stratified water injection scale in the East was larger than that in the north, so the stratified water injection effect in the East was better.

\subsection{4 cracks}

Fractures are conducive to improving the permeability of oil and water. The injected water mostly migrates along the fracture direction, and the main oil wells generally have fast effect and water flooding speed. The study area 
is mainly developed near northeast, east-west fractures, and West fractures.

\subsection{5 timing of water injection}

The stress sensitivity damage of low permeability reservoir conforms to the negative exponential attenuation law. The later the water injection time is, the greater the pressure drop is, the worse the physical property of reservoir is, and the more difficult the seepage is. Advanced water injection is often used for low permeability reservoirs, which can maintain formation pore pressure, supplement formation energy and maintain stable production. However, for main directional wells, due to the development of fractures, the injected water will arrive first, resulting in the increase of water cut speed and rapid water flooding of main directional wells. Therefore, delayed water injection should be adopted for main directional wells in the development process.

\section{2 layered water injection effect evaluation}

There are different standards for the effect evaluation of separate layer water injection in different oil production plants. Most of them adopt static standard, dynamic standard and management standard as the evaluation system. Through the average permeability, effective degree, qualified rate of separate injection and stable production period after effective evaluation, the study area is determined as class II. It is more persuasive to evaluate the effect through well pattern improvement, water injection utilization and effect income indicators, such as water drive reserves producing degree, water drive control degree, water storage rate and water drive index.

\subsection{1 producing degree of water drive reserves}

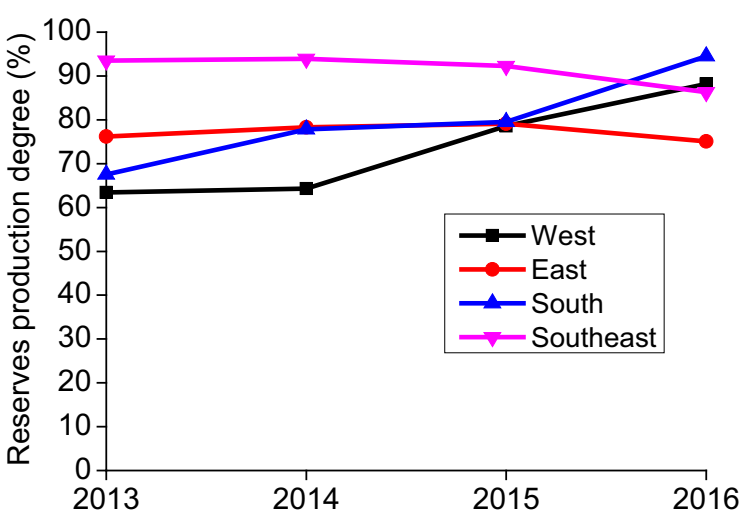

Figure 3. Production degree curve of water drive reserves in each unit over the years

With the deepening of oilfield development, the producing degree of water drive reserves is increasing. Crude oil production from the initial easy to exploit area to the middle and late difficult to exploit area, the degree of water drive reserves production from a substantial increase to a flat. According to the producing degree of water drive reserves, the water injection effect can be divided into five categories: the producing degree of water drive reserves is better than $80 \%$; it is better that the producing degree of water drive reserves is between $75 \%$ and $80 \%$; the producing degree of water drive reserves is between $70 \%$ and $75 \%$, which is medium; the producing degree of water drive reserves is $65 \%-70 \%$, which is poor; the production degree of water drive reserves is less than $65 \%$.It can be seen from Figure 3 that the water drive reserves in the East and southeast are decreasing, while the water drive reserves in the West and South are increasing.

\subsection{2 water storage rate and water drive index}

The water storage rate of the study area ranges from 0.91 to 0.97 , with an average value of 0.945 . On the whole, the water storage rate is high, and the water injection development effect is remarkable. The larger the water drive index is, the larger the water injection consumption is. Water drive index in 2010 is 3.87 , water drive index in 2011 is 4.72 , water drive index in 2012 is 5.32, water drive index in 2013 is 6.05, water drive index in 2014 is 6.86, water drive index in 2015 is 6.99 , and water drive index in 2016 is 7.39. It can be found that water drive index increases continuously, which is directly proportional to water cut. The increase of water drive index represents the increase of water injection, and its water cut increases with the increase of water injection.

\subsection{3 oil recovery rate}

The oil recovery rate directly reflects the effect of water injection development. The higher the oil recovery rate is, the higher the production is and the more obvious the water injection effect is. The oil recovery rate in 2009 was 0.36 , that in 2010 was 0.45 , that in 2011 was 0.54 , that in 2012 was 0.52 , that in 2013 was 0.49 , that in 2014 was 0.46 , that in 2015 was 0.44 , and that in 2016 was 0.41 .In addition to the low oil recovery rate in 2009 (put into development in the early stage), the oil recovery rate decreased year by year.

\subsection{4 water drive control degree}

The control degree of water drive reserves is the main basis for oilfield adjustment and tapping potential. The water drive control degree of the Western combined production unit is more than $85 \%$, accounting for $54.17 \%$; $33 \%$ in the East; $13 \%$ in the South and $63.34 \%$ in the southeast. According to the division rules of water drive control degree, the water drive control degree in the East and southeast is higher than that in the West and East.

\section{Conclusion}

The results show that the heterogeneity in different blocks is different, and the heterogeneity in the West and south is stronger than that in the East and Southeast; the interlayer distribution is used to evaluate the interlayer heterogeneity, and the proportion of uneven water absorption is positively correlated with the interlayer 
distribution. The more developed the interlayer is, the stronger the interlayer heterogeneity is, especially for the thickness $>2 \mathrm{~m}$, the more conducive to interlayer water injection; the larger the interlayer pressure difference is, the more unfavorable it is to separate layer water injection; the injected water migrates along the fracture direction, which has the characteristics of fast response and water flooding speed of the main directional well; advanced water injection is widely used in low permeability reservoirs, and delayed water injection is recommended for main wells with the same fracture direction.

The results show that the producing degree of water drive reserves in the East and southeast is decreasing, while the producing degree of water drive reserves in the West and south is increasing; the water storage rate is between 0.91 and 0.97 , with an average value of 0.945 ; the water drive index increases with the development, which represents the increase of water injection; with the deepening of development, the oil recovery rate gradually decreases; the degree of water drive control in the East and southeast is better than that in the West and south.

\section{References}

1. Grabhorn. Doe field demonstration program logs successes[J]. Oil and Gas Journal, 1995, 93(43):7278.

2. Bulaev V V, Zakirov S N, Zakirov E S. The development of high-viscous oil resources of petroleum fields[J]. Doklady Earth Sciences, 2006, 407(2):349-351.

3. Davidova I, Hicks M S, Fedorak P M, Suflita J M. The influence of nitrate on microbial processes in oil industry production waters[J]. Journal of Industrial Microbiology \& Biotechnology, 2001, 27(2):80-86.

4. Bulaev V V, Zakirov S N, Zakirov E S. Possibility of the development of a high-viscous oil reservoir by water flooding[J]. Doklady Earth Sciences, 2006, 407(1/2):205-208.

5. Carswell P W, Neeley J R. Fiber optic network links oil field controls[J]. Oil and Gas Journal, 1994, 92(10):64-66.

6. Cao H, Ikeda S. Inter-zonal tradable discharge permit system to control water pollution in Tianjin, China[J]. Environmental Science \& Technology, 2005, 39(13):4692-4699.

7. Lawrence M. Least cost design of activated sludge systems. Journal - Water Pollution Control Federation, 1976, 48(5):889-905.

8. Friedman J M. Efficiency in water quality control for the wilamette river[J]. Annals of Regional Science, 1975, 9(1):45-55. 